\title{
SOBRE UNA CONCEPCIÓN \\ COMPLEJA DE LAS NORMAS
}

El mejor homenaje que puede ofrecerse a un pensador es someter a análisis crítico sus ideas.

CARLOS SANTIAGO NINO

\section{Palabras preliminares}

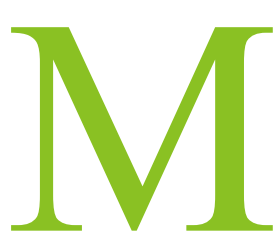

e propongo discutir en este ensayo un estimulante estudio el del profesor Carlos Nino, sugerentemente titulado «Algunas preocupaciones meta-filosóficas y su reflejo en una concepción compleja de las normas jurídicas» ${ }^{1}$, ensayo recogido íntegramente en su obra póstuma Derecho, moral y política ${ }^{2}$. Lo atractivo del tema y la seriedad de la reciente contribución de Nino me han llevado a intentar una crítica razonada de su construcción, pues como el propio Nino se encargó de señalarnos insistentemente a quienes aprendimos de él, «no hay idea que se considere demasiado peregrina para ser discutida seriamente, ni demasiado sagrada para ser puesta en duda», sentencia que refleja sólo en alguna medida su firme convicción de que la persecución del conocimiento, sin temor ni limitación, constituye un elemento esencial para el desarrollo humano, al punto que, si falta, priva de valor a casi todo lo demás. Espero que este ensayo refleje sus vivas enseñanzas y sirva de homenaje a su luminosa memoria.

\section{La construcción de Nino}

(1) Preocupaciones metafilosóficas. En opinión de Nino, la producción teórica en el ámbito del derecho se podría potenciar si se revisaran dos presupuestos filosóficos generalmente aceptados: el esencialismo conceptual y el escepticismo práctico. Ambas perspectivas -afirma Nino- determinan formas de encarar problemas que variarían sustancialmente si ellas fueran parcial o totalmente rechazadas (p. 1).

${ }^{1}$ El artículo aparecerá en el volumen Derecho. Ética y Lógica. Homenaje a Ernesto Garzón Valdés editado por el Centro de Estudios Constitucionales (Madrid) bajo la responsabilidad de Bulygin, E. et al. Me atengo a la paginación de la versión remitida por Carlos Nino (indicada entre paréntesis en mi texto), dado que la obra se halla todavía en prensa.

${ }^{2}$ Ver Nino, C. Derecho, moral y política. Una revisión de la teoría general del derecho, Ariel, Barcelona, 1994, específicamente los siguientes apartados: parágrafo 2 del Capítulo 1, parágrafo 1 del Capítulo 2 y parágrafos 3 y 5 del Capítulo 3. Puede resultar importante destacar que, si bien el libro carece de notas y referencias bibliográficas, el ensayo las contiene, y muy puntuales. 
(a) Esencialismo conceptual. El primer presupuesto se vincula, explica Nino, con «la idea de que los conceptos son verdaderos o falsos según reflejen ciertos rasgos esenciales que presentan las cosas o fenómenos referidos por esos conceptos» (p. 1). Según Nino, «aunque la mayoría de los iusfilósofos rechazan explícitamente el esencialismo conceptual, por lo menos en su versión tradicional, lo siguen practicando con entusiasmo cuando defienden un cierto concepto de derecho, de norma jurídica, de deber jurídico, etcétera, como si fuera el único posible» (p. 2).

(b) Escepticismo práctico. En cuanto al segundo, cree Nino que «es evidente que el escepticismo acerca de razones para justificar acciones o decisiones -sean de tipo moral o prudencial- es una posición filosófica bastante más sólida que el esencialismo» (p. 3). Sin embargo -agrega-, «independientemente de la validez o no de la tesis escéptica, se comete un error de procedimiento filosófico cuando se asume ese escepticismo en el tratamiento de problemas distintos a la cuestión de su validez» (p. 3); «no se justifica presuponer la validez del escepticismo práctico para tratar problemas como el de las variedades de normas jurídicas, y el de cuáles son sus propiedades y relaciones lógicas. Creo que hay razones -concluye Nino- que indican la conveniencia de partir del presupuesto opuesto, o por lo menos la conveniencia de partir, alternativamente, de uno y otro presupuesto para advertir la implicaciones de ambos sobre los problemas mencionados» (p. 3).

Sobre esta base, Nino reclama «una presunción filosófica favorable a la predicación de verdad o falsedad de los juicios prácticos, en contextos como el del análisis de las normas en general y de las normas jurídicas en especial», lo que no constituye sino «una regla de procedimiento filosófico que aconseja partir del presupuesto de que hay razones en favor de la verdad o falsedad de proposiciones de índole moral o prudencial en contextos teóricos en que no se está discutiendo precisamente ese presupuesto» (p. 8). Aceptar esta regla -concluye Nino«conduce a una visión de las normas jurídicas bastante más compleja de las que se suelen obtener partiendo de la presunción opuesta» (ps. 8-9).

(2) Una concepción compleja de las normas. Nino distingue cuatro categorías de normas que considera necesario aislar para comprender el fenómeno normativo: prescripciones, juicios constatativos de prescripciones, juicios normativos puros y juicios normativos de adhesión ${ }^{3}$. En su construcción, «todas las clases de juicios mencionadas, salvo la primera, son proposiciones: es decir ellas no son oraciones o entidades gramaticales o actos lingüísticos, sino el significado de tales oraciones o actos lingüísticos» (p. 9). adhesión».

3 Para abreviar, hablaré de «prescripciones», «juicios constatativos», «juicios normativos» y «juicios de 
(a) Prescripciones. «Una prescripción es un acto lingüístico que consiste en formular un juicio normativo con la intención de que ese mismo acto lingüístico constituya parte de una razón del destinatario para realizar la acción normada, dado algún juicio normativo al que el destinatario adhiere». En este sentido, «lo que interesa es especialmente el aspecto de formulación del juicio, la que puede hacerse oralmente o por escrito. Sin formulación no hay prescripción (mientras por supuesto hay juicio que nadie ha formulado y que quizá nadie formule)». Conviene aclarar, agrega Nino, que «hay otra noción de norma que está estrechamente relacionada con la que se refiere a prescripciones, pero no denota el acto de prescribir sino el producto material de ese acto, que puede consistir en grafismos o textos o en sonidos. La característica ambigüedad de proceso-producto que tienen algunas palabras obscurece a veces la distinción entre estas dos nociones interrelacionadas de norma» (p. 10). De este modo, según Nino, «es importante advertir que la prescripción es la formulación de un juicio normativo» (p. 11).

(b) Juicios constatativos. Según Nino, «estos juicios constativos pueden por cierto ser verdaderos o falsos, dependiendo tal verdad de que efectivamente haya acaecido el acto lingüístico prescriptivo en cuestión. El acto lingüístico referido por la proposición constatativa puede haberse dado en el pasado, respecto del momento de la formulación de esa proposición, o en el futuro. En este último caso la proposición constatativa formula una predicción» (p. 13). Conforme a su explicación, «la verdad o falsedad de las proposiciones constatativas depende no solamente de que se hayan pronunciado determinadas palabras sino que se lo haya hecho con la intención correspondiente y que las palabras y la intención correspondan al juicio normativo que se dice prescripto o que haya convenciones apropiadas para la asignación de esa intención» ( $\mathrm{p}$. $13)$.

(C) Juicios normativos. Explica Nino que tales juicios «son proposiciones que predican de una conducta que es debida, permitida o prohibida» (p. 16). La importancia de tales juicios radica en que «una decisión o una acción sólo puede justificarse en última instancia en juicios normativos, o sea juicios que califican a una acción como debida, permitida o prohibida. Sólo la aceptación de un juicio de esta índole es pragmáticamente inconsistente con la realización de la acción o decisión opuesta a la que se quiere justificar» (p. 14).

Desde su punto de vista, «un juicio normativo puro puede ser una norma jurídica cuando se trata de un juicio de moral intersubjetiva que se refiere a la forma en que debe organizarse y emplearse el cuasi-monopolio de la coacción que se constituye en un grupo social» (p. 17). Concluye Nino señalando que «estos juicios son verdaderos o falsos. El juicio de que todos 
debemos abstenernos de matar es verdadero si y sólo si todos debemos abstenernos de matar» (p. 16).

(d) Juicios de adhesión. Explica Nino que «de un juicio normativo puro que establece que una autoridad debe ser obedecida se deduce, con la intermediación de un juicio constatativo de la prescripción de la autoridad, un juicio normativo de adhesión» (p. 20) y que «los juicios normativos de adhesión tienen una dimensión pragmática ya que sirven para justificar acciones o decisiones» (p. 20). En opinión de Nino, también «los juicios de adhesión son verdaderos o falsos, estando determinado su valor de verdad por la verdad o falsedad del juicio normativo puro del que deriva, por la verdad o falsedad del juicio constatativo de una prescripción que media esa derivación y por la corrección de la deducción a partir de tales juicios» (p. 19)

Un ejemplo de tal derivación sería el siguiente: (1) Es moralmente debido obedecer a la autoridad A, (2) La autoridad A ha prescripto «Es obligatorio hacer p», ergo (3) Debo (moralmente) hacer p. El razonamiento incluye como premisa (1) un juicio normativo de índole moral y como premisa (2) un juicio constatativo; finalmente, concluye con un juicio de adhesión, (3), el cual es normativo ya que deriva de premisas una de las cuales tiene ese carácter (p. 18). Nada impide, por cierto, que la premisa normativa sea de índole prudencial (temor a la sanción, por ejemplo), en cuyo caso tendría la forma (1') Es prudencialmente debido obedecer a la autoridad A, derivando de ella, en conjunción con (2), la conclusión (3') Debo (prudencialmente) hacer $\mathrm{p}$.

\section{Observaciones sobre la concepción de Nino}

(1) Escepticismo y positivismo. He señalado que en opinión de Nino se comete un error de procedimiento Filosófico cuando se asume el escepticismo en el tratamiento de problemas distintos a la cuestión de su validez. A esta opinión subyace la tesis negada por Nino de que existe conexión conceptual entre el escepticismo practico y el positivismo. A mi entender, tanto la tesis de que las normas carecen de valores de verdad (no son verdaderas ni falsas), como la tesis de que existe una separación tajante entre descripción y prescripción (entre el ser y el deber ser), ambas tesis escépticas, son definitorias del positivismo ${ }^{4}$. La tesis del no cognoscitivismo normativo tiene como fundamento principal la defensa de un punto de vista según el cual no existen hechos normativos que hagan verdaderas a las normas, lo que supone que no hay realidad alguna que corresponda a éstas últimas. $\mathrm{La}$

\footnotetext{
${ }^{4}$ Ver, en este mismo sentido, von Wright, G.H. «Is and Ought», en Bulygin. E. et. al. Man, Law and Modern Forms of Life, Reidel, Dordrecht, 1986, ps. 277-9; Bulygin, E. «Sobre el status ontológico de los derechos humanos», en Doxa 4, ps. 82-3.
} 
tesis de la separación descripción/prescripción constituye la base del programa positivista de una ciencia avalorativa del derecho, en la cual quedan enfrentados conocimiento y valoración, ciencia y política.

En una cuestión conexa, Nino ha rechazado insistentemente toda vinculación conceptual entre el positivismo jurídico y el escepticismo ético, sosteniendo que no es esencial a la posición positivista la negación de la tesis según la cual hay principios morales universalmente válidos y racionalmente justificables (o de derecho natural, en cierto sentido de esta expresión) ${ }^{5}$. De este modo, de acuerdo con su punto de vista, no es correcto identificar al positivismo jurídico con el escepticismo ético. Sin embargo, la tesis opuesta es decididamente defendida por conspicuos representantes del positivismo y considerada como una nota definitoria de la concepción. En este sentido, la posición de Ross resulta paradigmática ${ }^{6}$ e ilustrativa para un cotejo, dado que el positivismo jurídico es concebido en ella como un enfoque de los problemas jusfilosóficos y de teoría del derecho basado en dos tesis fundamentales, una metaética y otra metodológica: la primera se relaciona con la creencia de que no existe un derecho natural (principios verdaderos y obligatorios, eterna y universalmente válidos) y supone la negación de que los juicios éticos sean la expresión de verdades sobre algo a ser descubierto mediante algún proceso de conocimiento $^{7}$; la segunda se vincula con la aceptación de una estrategia de acuerdo con la cual es posible establecer la existencia de un sistema jurídico y describir su contenido en términos objetivos, sin necesidad de recurrir a principios de derecho natural o de moralidad.

Sobre esta base, difícilmente los autores de cuño positivista compartan la preocupación de Nino sobre el escepticismo y probablemente rechacen la imputación de haber venido sosteniendo una posición basada en el error.

(2) Constructivismo ético. De acuerdo con la posición ética de Nino denominada «constructivismo» en adhesión a una sugerencia terminológica de Rawls ${ }^{8}$-, «un juicio moral es verdadero cuando sería aprobado en condiciones de imparcialidad, racionalidad y conocimiento de los hechos relevantes»

${ }^{5}$ Ver Nino, C. Introducción al análisis del derecho, Astrea, Buenos Aires, 1980, ps. 30-5 y Algunos modelos metodológicos de «ciencia» jurídica. Fontamara. México. 1993 (original 1979), ps. 75-90.

${ }^{6}$ Idéntico punto de vista en Bulygin, E. op. cit., ps. 79-84 y Hoerster, N. En defensa del positivismo jurídico, Gedisa, Barcelona, 1992, ps- 9-27.

${ }^{7}$ Según Ross, «la negación positivista de la existencia del derecho natural es una consecuencia implícita de la doctrina más general que niega la existencia de todo conocimiento ético». Ver Ross, A. El concepto de validez y otros ensayos. Centro Editor de América Latina, Buenos Aires, 1969, ps. 11-2.

${ }^{8}$ Ver Nino, C. El constructivismo ético, Centro de Estudios Constitucionales, Madrid, 1989, ps. 11-2. 
(p. 6), puesto que «quienes participan del discurso moral para dirimir sus conflictos se comprometen implícitamente a adoptar la solución que indicaría un árbitro ideal, o sea alguien que fuera completamente racional, que conociera todos los hechos relevantes y que fuera plenamente imparcial, en el sentido de dar igual peso a los intereses de igual jerarquía de los involucrados en el conflicto ${ }^{9}$. De este modo, según la concepción de Nino, si una persona poseyera las características mencionadas (racionalidad, conocimiento e imparcialidad), resultaría un juez moral perfecto en cada situación y sería capaz -infaliblemente- de decir qué es correcto y qué incorrecto: saber que el árbitro ideal aprueba x sería lo mismo que saber que x es correcto. Pero no sólo eso, puesto que el pronunciamiento del árbitro daría el significado de «correcto» e «incorrecto», en la medida en que esta teoría sea considerada metaética ${ }^{10}$.

La teoría es razonable en tanto no requiere la existencia efectiva del árbitro y sólo sostiene que, si hubiese tal ser, su juicio sería indefectiblemente acertado. La afirmación es hipotética y no asegura que haya un árbitro ideal, sino que si lo hubiera, entonces lo que él aprobara moralmente sería (por definición) correcto: «el hecho moral al que me estoy refiriendo -dice Nino- es peculiar porque consiste en una circunstancia contrafáctica; consiste en algo que sucedería si otro hecho que en la realidad no ocurre (el que alguien sea completamente racional e imparcial) ocurriera ${ }^{11}$. Pero la teoría va más lejos, ya que sostiene no sólo que el juicio del árbitro sería acertado en cada caso, sino que lo sería por definición: la oración «x es correcto» sería equivalente en significado a «el árbitro ideal aprueba $\mathrm{x}$ ». Esto parece objetable: podría concederse que todo aquello que el árbitro dijese fuera siempre acertado, pero parece inadmisible que ese sea el significado de «x es correcto». La definición, ciertamente, nada nos dice sobre la naturaleza de $\mathrm{x}$ (en rigor, nos dice más sobre el árbitro que sobre el acto juzgado). Esto resulta bastante extraño, ya que cuando decimos que x es correcto, entendemos -o eso parece- que $\mathrm{x}$ mismo posee alguna propiedad. Aunque estemos dispuestos a aceptar que el juicio del árbitro ideal resultaría verdadero, no lo aceptaríamos como aquello que entendemos por «x es correcto», o como criterio que usamos siempre para determinar si x es correcto. Al decir de Hospers, «si ya creemos que un acto es recto, entonces asentiremos a la proposición de que un observador ideal lo aprobaría, pero difícilmente a la inversa: cuando decimos que un observador ideal lo aprobaría, podemos

${ }^{9}$ Ibídem, p. 69.

${ }^{10}$ Para un análisis cuidadoso de esta posición, ver Hospers, J. La conducta humana, Tecnos, Madrid, 1979 (original 1961), ps. 789-796. Sigo de cerca las observaciones del autor.

${ }^{11}$ Nino, C. El constructivismo ético, citado ut supra, p. 69. 
entonces creer que es recto, pero no es esto lo que se quiere significar al decir que es recto» ${ }^{12}$.

Podría objetarse a la teoría la forma de describir lo que se quiere dar a entender cuando calificamos algo de correcto o incorrecto. Es probable que los usuarios del lenguaje no procedan como pretenden los constructivistas sino a la inversa: primero se preguntan a sí mismos sobre la corrección del acto x y luego -en todo caso- cómo lo juzgaría el árbitro ideal, comparando entonces ambas opiniones a fin de determinar si ellas coinciden siempre o no. De ser éste el procedimiento adoptado, seguirían existiendo dos características: la de ser x correcta y la de ser $\mathrm{x}$ aprobada por el árbitro ideal. Aunque ambas puedan tener la misma denotación ello no implicaría que signifiquen lo mismo, ya que dos propiedades pueden ir juntas sin que por ello se conviertan en una sola. De existir realmente dos características, el constructivismo no habría tenido éxito como teoría naturalista que pretende elucidar el significado de los términos éticos: si no define el término ético, sino que solamente nos indica qué otra propiedad va regularmente asociada con la corrección, entonces no nos dice lo que es la corrección. Y éste parecería ser un síntoma de fracaso.

(3) Hechos normativos. La idea de que las normas son verdaderas o falsas está basada en una analogía con la llamada convención $\mathrm{T}$ de Tarski, de acuerdo con la cual « $\mathrm{P} »$ es verdadera si, y sólo si, $\mathrm{P}$ (donde « $\mathrm{P} »$ representa el enunciado proposicional y $\mathrm{P}$ el estado de cosas al cual aquél hace referencia). En el caso de las normas la cláusula sería la siguiente: «N» es verdadera si, y sólo si, $\mathrm{N}$ (donde «N» representa el enunciado normativo y $\mathrm{N}$ el hecho normativo al cual aquél hace referencia $)^{13}$. A esta construcción subyace, obviamente, la noción de verdad como correspondencia. Sin embargo, no basta con señalar la analogía, puesto que resulta necesario justificar la existencia de los hechos que hacen verdaderas a las normas. Nino no duda en postular la existencia de hechos normativos, lo que remite su teoría, inevitablemente, a una ontología muy complicada, ontología que, por cierto, él no se ocupa sino de perfilar. Es así que sin la elaboración cuidadosa de una construcción teórica capaz de dar cuenta de hechos específicamente normativos, la pretensión de que las normas poseen valores veritativos permanece sin sustento sólido.

Se podría conceder a Nino, en todo caso -sobre la base de su postulación de que tal hecho normativo consiste en una circunstancia contrafáctica (la

\footnotetext{
${ }^{12}$ Hospers, J. Introducción al análisis filosófico, Alianza, Madrid, 1982 (original 1967), p. 693.

${ }^{13} \mathrm{Al}$ respecto, ver Kalinowski, G. Lógica de las normas y lógica deóntica. Posibilidad y relaciones, Fontamara, 1993, ps. 19-22.
} 
existencia de un juzgador moral ideal: racional, informado e imparcial) ${ }^{14}$-, que las normas serían verdaderas, si se dieran tales circunstancias. Esto parecería conducir a la concepción de Nino hacia la teoría de los mundos posibles. En este sentido, se afirma -desde algún punto de vistaque los mundos posibles son tan reales como el mundo actual y que todo forma parte de nuestra ontología. Si se sostiene que la realidad es más amplia y que está constituida no sólo por lo que de hecho se da, sino también por lo que puede darse, entonces cabe predicar verdad o falsedad de las normas en un mundo determinado, si además puede indicarse cuál de esos mundos tiene la característica de ser un mundo óptimo. De este modo, la construcción permitiría asignar valores de verdad a las normas pero exigiría nuevamente la aceptación de una ontología excesivamente compleja, cuyos fundamentos restaría por elaborar. La situación sería similar incluso para aquellos que, en forma no literal, interpretan el hablar acerca de los mundos posibles como hablar acerca de los diferentes modos en que podríamos concebir el mundo ${ }^{15}$.

Se han conseguido avances importantes en la explicitación de los presupuestos que subyacen a la atribución de valores de verdad a las normas ${ }^{16}$. Considerando que en su función regulativa ellas hacen referencia a acciones futuras, sus condiciones de verdad estarían dadas, entre otros factores, por la situación actual del agente, las situaciones y opciones futuras y el orden jerárquico de las diferentes alternativas de acción. Sobre esta base, sería posible detectar dos posiciones básicas en materia de valores: el realismo y el conceptualismo. Para la primera, los valores $\mathrm{y}$, por consiguiente, el orden jerárquico de las alternativas, formarían parte objetiva de la realidad, mientras que para la segunda los valores serían constituidos por el hombre y, en consecuencia, los juicios acerca del orden jerárquico de las alternativas no serían verdaderos ni falsos y necesitarían ser justificados de otra manera. Esto llevaría a distinguir, a su vez, dos variantes en el conceptualismo: el conceptualismo absolutista y el conceptualismo relativista. De acuerdo con la postura absolutista -la cual adopta Nino- todos aquellos que se encontraran en condiciones ideales (contrafácticas) de racionalidad, imparcialidad y conocimiento aceptarían la misma jerarquía de alternativas. La postura relativista, en cambio, admitiría que podrían darse discrepancias incluso entre sujetos en condiciones ideales. Se seguiría de esto que la justificación del orden jerárquico residiría para los absolutistas en el consenso en condiciones

\footnotetext{
${ }^{14}$ Ver Nino, C. El constructivismo ético, citado ut supra, ps. 61-71 y en particular p. 69.

${ }^{15}$ Haack advierte sobre el notable desacuerdo existente acerca de qué tipo de cosas sean los mundos posibles. Ver al respecto su obra Filosofia de las lógicas, Cátedra, Madrid, 1982 (original 1978), p. 216.

${ }^{16}$ Ver Alchourrón, C. y Bulygin, E. «Deontic Truth and Values», en Kangas, U. Essays in Legal Theory of Kaarle Makkonen, Oikeustiede Jurisprudentia XVI, Helsinki, 1983.
} 
ideales, mientras que para los relativistas en acuerdos efectivos del grupo social. De este modo, sería la aceptación o el rechazo del principio en virtud del cual todos los individuos en condiciones ideales aceptarían la misma jerarquía para cualquier conjunto de alternativas lo que determinaría tal discrepancia interna en el conceptualismo.

Es importante advertir que realistas y absolutistas coinciden en una cuestión importante: ambos sostienen que existe, para cada caso, una jerarquía objetiva que resulta privilegiada por sobre todas las demás, dado lo cual deben hacerse cargo de explicar el modo como tal jerarquía puede ser conocida y de ofrecer las razones que la convierten en la única aceptable. Planteada como se halla por los relativistas la posibilidad de que tal jerarquía objetiva pueda no existir, recae sobre aquéllos la carga de su prueba.

(4) Puntos de vista interno y externo. Hart ha señalado agudamente que cuando un grupo social dispone de normas reguladoras de conducta, este hecho abre la posibilidad de referirse a ellas de dos maneras muy diferentes, aunque estrechamente relacionadas entre sí, dado que es posible ocuparse de ellas como un mero observador que las describe sin comprometerse con su aceptación, o como un miembro del grupo que las acepta y las usa como guías de acción ${ }^{17}$. La primera perspectiva corresponde a un punto de vista externo y la segunda a un punto de vista interno, respecto -obviamente- de las normas en cuestión. En la construcción de Nino, de acuerdo con su propia observación, los juicios normativos corresponden a los enunciados que se formulan desde el punto de vista interno (p. 17).

Respecto de este tema hay una cuestión interesante que apuntar. Sucede que Hart concibe a los enunciados internos diciendo: «un enunciado interno (...) manifiesta el punto de vista interno y es usado con naturalidad por quien, aceptando la regla de reconocimiento y sin enunciar el hecho de que ella es aceptada, la aplica al reconocer como válida alguna regla particular del sistema» ${ }^{18}$.

Esto supone que los enunciados internos versan sobre la validez de las normas y que un enunciado tal como «La norma $\mathrm{N}$ es válida» equivale a una directiva de la forma « $\mathrm{N}$ debe ser obedecida». Sin embargo, Hart no considera la posibilidad de formular enunciados externos sobre la validez de las normas, enunciados verdaderos o falsos formulados sobre la pertenencia de la norma en cuestión a un sistema dado, sin comprometerse en forma alguna con su aceptación ${ }^{19}$.

\footnotetext{
${ }^{17}$ Hart, H.L.A. El concepto de derecho, Abeledo-Perrot, Buenos Aires, 1977 (original 1961), ps. 110-111.

${ }^{18}$ Ibídem, p. 128.

19 Ver Bulygin, E. «Norms, Normative Proposition and Legal Statements», en Floïstad, G. Contemporany Philosophy. A New Survey, vol. 3, Nijhoffs Publishers, La Haya, 1992, ps. 127-152.
} 
La posición de Nino sobre esta cuestión difiere de la de Hart en un punto importante: Nino acepta que estos enunciados poseen valores veritativos porque admite la existencia de hechos normativos capaces de hacerlos verdaderos o falsos, cosa que Hart rechazaría, sin lugar a dudas. Aunque la terminología de Hart pueda llevar a confusión, él compartiría la tesis de que al no ser fácticos tales enunciados, no cabría predicar de ellos verdad o falsedad: Hart aceptaría que resulta insostenible la tesis de que un mismo enunciado pueda ser descriptivo y normativo al propio tiempo, así como que un enunciado normativo pueda ser verdadero o falso. Nino, en cambio -a mi entender equivocadamente-, niega ambas tesis.

(5) Validez y justificación. Nino asocia abiertamente la noción de validez de una norma con la de justificabilidad, con la fuerza vinculante de lo que ella dispone, con su fuerza obligatoria. En este sentido, decir que una norma es válida implica que ella constituye una razón para justificar una acción o decisión: decir que una norma es válida es prescribir que ella debe ser obedecida o aplicada. Por lo tanto, de acuerdo con esta noción, la oración « $\mathrm{N}$ es válida» no expresa una proposición sino una prescripción. De este modo, si la designación de «validez» incluye la justificabilidad, el concepto se convierte en una noción normativa. El empleo del concepto de validez con este alcance supone que la expresión « $\mathrm{N}$ es válida pero no debe ser obedecida» es autocontradictoria. Esto implica que tal noción de validez presupone una definición no positivista del derecho, cosa que Nino admite sin reparos ${ }^{20}$.

De acuerdo con un enfoque alternativo, cabe decir que una norma es válida en el sentido de que pertenece a un sistema jurídico determinado ${ }^{21}$. Este concepto de validez es descriptivo, porque la oración «N es válida» es una proposición y no una norma. Además, es un concepto relativo, por cuanto hace referencia a una relación entre una norma y un sistema dados. La noción central de este modo de concebir la validez es, pues, la de pertenencia. En este sentido, se han distinguido dos criterios básicos de pertenencia de normas a sistemas: criterio de legalidad y criterio de deducibilidad ${ }^{22}$. Conforme al primero, una norma pertenece al sistema si ha sido dictada por una autoridad competente y, de acuerdo con el segundo, una norma

${ }^{20}$ Ver Nino, C. Introducción al análisis del derecho, citado ut supra, p. 134.

${ }^{21}$ Bulygin, E. «An Antinomy in Kelsen's Pure Theory of Law», en Ratio Juris 3, ps. 29-45.

${ }^{22}$ El tema de los criterios de pertenencia ha sido cuidadosamente desarrollado en Caracciolo, R. El sistema jurídico. Problemas actuales, Centro de Estudios Constitucionales, Madrid, 1988, y en Bulygin, E. «Algunas consideraciones sobre los sistemas jurídicos», en Doxa 9, ps. 257-279. Desarrollos posteriores pueden encontrarse en Moreso, J.J. y Navarro, P. Orden jurídico y sistema jurídico. Una investigación sobre la identidad y la dinámica de los sistemas jurídicos, Centro de Estudios Constitucionales, Madrid, 1993. 
pertenece al sistema cuando es consecuencia lógica de normas pertenecientes al sistema. Estos criterios, sin embargo, son manifiestamente insuficientes para dar cuenta de todas las normas del sistema, pues presuponen que éste tiene ya ciertas normas, cuya pertenencia no se puede establecer en base a ninguno de los dos criterios anteriores. Siguiendo a von Wright, puede denominarse normas soberanas a tales normas. Esto supone, claro está, que todo orden jurídico debe originarse en un conjunto de normas soberanas, el cual constituye la base del orden en cuestión.

Desde esta perspectiva, que algo sea una norma jurídica depende, básicamente, de criterios empíricos y formales y no de criterios valorativos. Consecuencia inevitable de ella es que de la asignación de calificación jurídica a una norma no se sigue que exista el deber moral de acatarla. Esta posición determina una diferencia importante con aquella ideología pseudopositivista de acuerdo con la cual todo derecho, por el mero hecho de serio, resulta moralmente obligatorio ${ }^{23}$. Aquélla es una aproximación valorativamente neutral y se distingue claramente de esta otra, la cual considera que cuando llamamos a algo «derecho» o «norma jurídica» no nos limitamos a describirlo, sino que estamos recomendando su acatamiento.

(6) Justificación de acciones y decisiones. Según Nino, «una decisión o una acción sólo puede justificarse en última instancia en juicios normativos, o sea juicios que califican a una acción como debida, permitida o prohibida» (p. 14). Cuando Nino habla de «justificación última» tiene en mente justificaciones de cierta especie: los juicios normativos que sirven de justificación última son juicios morales o prudenciales, al punto que en su opinión, «ningún juicio normativo es una razón justificatoria última de acciones o decisiones si él es aceptado por razones de autoridad o en atención a las consecuencias que se seguirían de su no aceptación» (p. 15). Esto me parece exagerado. Ante todo, no creo que en moral sea posible una fundamentación última, dado que la exigencia de una fundamentación tal conduce al conocido trilema de Münchhausen: sólo se tiene la elección entre un regreso al infinito, un círculo lógico y una interrupción del proceso fundamentador.

Además, clasificar unitariamente como morales a todas las razones que remiten a la aceptación de normas no parece de mucha ayuda, al menos no desde un punto de vista explicativo. Desde esa perspectiva, parece más conveniente mantener una distinción terminológica según los tipos de normas a los que se recurre y hablar de «razones morales» de la acción cuando ellos

${ }^{23}$ Ver Ross, A. op. cit., ps. 21-5 y Bobbio, N. El problema del positivismo jurídico, EUDEBA, Buenos Aires, 1965 , ps. 37-64. 
resultan de las instituciones morales y de «razones jurídicas» cuando lo hacen de instituciones de derecho ${ }^{24}$.

Por otra parte, no puede desconocerse que los jueces normalmente justifican sus decisiones en las normas del sistema, identificadas de acuerdo con los criterios previstos en el mismo, sin incluir juicios morales o prudenciales. Es más, si en lugar de proceder de tal manera los jueces optaran por fundar sus decisiones en juicios morales, sus decisiones serían fuertemente criticadas y sus pronunciamientos resultarían probablemente descalificados. Ello pone en evidencia que, en un sentido importante y privilegiado, las disposiciones identificadas mediante criterios positivos poseen una fuerza justificatoria insustituible.

Bulygin ha ofrecido una explicación esclarecedora del proceso de justificación de decisiones jurídicas ${ }^{25}$. Supóngase un caso $\mathrm{C}$ en el que un sujeto $\mathrm{S}$ ha cometido el delito $\mathrm{D}$, situación ante la cual el juez J se pregunta qué hacer con $\mathrm{S}$. De conformidad con la norma $\mathrm{N}$, el que comete el delito D debe ser sancionado con la pena $\mathrm{P}$, y de acuerdo con la norma $\mathrm{N}^{\prime}$ el juez $\mathrm{J}$ debe aplicar $\mathrm{N}$ en el caso $\mathrm{C}$. Usando $\mathrm{N}$ y N' el juez $\mathrm{J}$ está en condiciones de resolver $\mathrm{C}$ aplicando a $\mathrm{S}$ la pena $\mathrm{R}$. Si en lugar de proceder de esa forma J siguiera preguntando qué debe hacer con S, no cumpliría con sus deberes judiciales, exponiéndose al peligro de perder su cargo por ello. Como bien señala Bulygin, la infinita serie de preguntas acerca del fundamento de las normas conduce a una parálisis total, de la cual sólo puede salirse dejando de preguntar y usando una norma como pauta de conducta, para lo cual es necesario identificar las normas que interesan en ese contexto. De este modo, el juez debe usar las normas jurídicas y para identificarlas necesita recurrir a un criterio conceptual: «es obvio -dice Bulygin- que el juez no puede usar normas jurídicas si previamente no las identificó y no puede identificarlas si no dispone de un criterio que le diga cuáles son ${ }^{26}$. El proceso sigue, pues, el siguiente orden lógico: recurriendo a un criterio de reconocimiento el juez identifica las normas aplicables al caso y luego lo resuelve usando las normas identificadas para justificar su decisión.

En resumen: Nino defiende la idea de que una teoría del razonamiento jurídico justificatorio debe admitir cierta conexión necesaria entre el derecho y la moral -en el sentido de que la premisa principal de un razonamiento jurídico justificatorio necesita ser una pauta moral- y que, consecuentemente,

\footnotetext{
${ }^{24}$ Ver Kliemt, H. Las instituciones morales, Fontamara, México, 1992 (original 1985), p. 206.

${ }^{25}$ Bulygin, E. «Algunas consideraciones sobre los sistemas jurídicos», citado ut supra, ps. 272-4.

${ }^{26}$ Ibídem, ps. 273-4.
} 
la justificación de las decisiones judiciales implica el uso de normas y principios morales. De este modo, la pretensión de justificar decisiones normativas con independencia de la moral es lógicamente imposible. Todo esto supone la utilización de un concepto material de justificación (más comprensivo que el estrictamente formal), el cual requiere no sólo la existencia de una relación deductivamente válida sino también la utilización de premisas calificadas. Para un enfoque alternativo, relacionado con la noción formal de justificación, es suficiente contar con un conjunto de criterios que permita individualizar la norma aplicable y, a partir de allí, una vez efectuada tal individualización y la descripción adecuada de las circunstancias subsumibles en ella, es posible inferir una conclusión que estará justificada en relación con esas premisas ${ }^{27}$.

Al decir de Kliemt, «cuando consideramos a las normas jurídicas desde un punto de vista interno, entonces ello es decisivo para nuestro comportamiento. En este caso tenemos, en el amplio sentido de la palabra, razones jurídicas para nuestro comportamiento. Pues son las instituciones jurídicas las que nos mueven -porque las aceptamos como reglas- a hacer determinadas cosas. El hecho de que las aceptemos y, sin mayor fundamentación ulterior, las utilicemos como pautas de nuestro comportamiento las convierte, en cierto modo, hasta en razones «últimas» de nuestro comportamiento. Pero sería bien curioso que por sólo ello las llamáramos «morales»; al menos no sería muy esclarecedor» ${ }^{28}$.

(7) Competencia y juicios normativos. En la teoría de Nino, «un juicio normativo puro (...) da competencia a una autoridad estableciendo que es debido obedecerla» (p. 20). Esta tesis de que las normas de competencia son reducibles a normas de conducta fue defendida en forma similar, en alguna ocasión, por Ross, para quien aquéllas deben ser interpretadas como «directivas que disponen que las normas que se creen de conformidad con un modo establecido de procedimiento serán consideradas normas de conducta» ${ }^{29}$.

Ya con anterioridad Nino había objetado la prevención de Hart contra la reducción de las normas de competencia (y otras normas secundarias) a normas de obligación ${ }^{30}$. Según Nino, «las normas que transmiten competencia son normas de obligación: son del tipo de normas que Ross llamó “normas

\footnotetext{
${ }^{27}$ Ver Moreso, J.J., Navarro, P. y Redondo, M.C. «Argumentación jurídica, lógica y decisión judicial», en Doxa 11 , ps. 248 y $255-6$.

${ }^{28}$ Ver Kliemt, op. cit. p. 205.

${ }^{29}$ Ross, A. Sobre el derecho y la justicia, EUDEBA, Buenos Aires, 1963 (original 1958), p. 32.

${ }^{30}$ Nino, C, «El Concepto de Derecho de Hart», en Revista de Ciencias Sociales 28, ps. 33-54.
} 
indirectas de conducta" (...) Se trata de normas que establecen obligaciones "en blanco", haciendo depender la especificación de la conducta obligatoria de la voluntad de otros» ${ }^{31}$. La situación es, pues, la siguiente: llamemos $\mathrm{C}$ a una norma de competencia en virtud de la cual la autoridad A queda habilitada para dictar la norma $\mathrm{N} \mathrm{o}$, para decirlo en la forma tradicional, la norma de competencia $\mathrm{C}$ dispone: «A es competente para dictar $\mathrm{N}$ »; en la construcción de Nino, $\mathrm{C}$ no puede sino interpretarse diciendo que, si A dicta $\mathrm{N}$, entonces $\mathrm{N}$ debe ser obedecida por los sujetos destinatarios. Este «debe», sin embargo, expresa un deber moral y no jurídico.

La posición de Nino me parece objetable, sobre todo ${ }^{32}$ porque convierte a las normas que confieren poder en normas morales, puesto que los juicios normativos son de esa especie y son ellos los que, en definitiva, otorgan competencia. Esto supone que uno de los conceptos jurídicos fundamentales, el de competencia, es un concepto moral, y presupone algo así como la aplicabilidad de ciertos principios de justicia y moralidad social que establecen en qué condiciones cabe observar y reconocer las normas de quienes detentan el monopolio de la coacción social. En última instancia, además, toda autoridad jurídica sería, según la tesis de Nino, una autoridad moral. Por decirlo en forma moderada, esto me resulta teóricamente poco fructífero y políticamente peligroso.

(8) Las normas como actos. La teoría de Nino parte de una valiosa contribución de Alchourrón y Bulygin relativa a dos concepciones diferentes de las normas: la concepción expresiva y la concepción hilética ${ }^{33}$. Para la concepción expresiva las normas son el resultado del uso prescriptivo del lenguaje, mientras que para la concepción hilética son significados de ciertas expresiones denominadas enunciados normativos. Según Alchourrón y Bulygin, las dos concepciones son radicalmente diferentes e incompatibles y no existe espacio para ningún tipo de eclecticismo. Nino parece poner en duda esta conclusión al sostener que «no es posible rechazar a priori la posibilidad de que algunos conceptos de norma respondan a la concepción expresiva, otros a la concepción hilética, y tal vez otros a cierta combinación entre las dos concepciones» (p. 9). Esta duda me parece, en cierta medida, justificada.

${ }^{31}$ Ibídem, p. 48.

32 Pasaré por alto otras objeciones formulables a la concepción. Para un análisis de las normas de competencia, ver Mendonca, D. Introducción al análisis normativo, Centro de Estudios Constitucionales, Madrid, 1992, p. 123 y ss. y Mendonca, D. «Fundamentación normativa de la autoridad», en Bulygin, E. et al. Derecho, moral y lógica. Homenaje a Ernesto Garzón Valdés, Centro de Estudios Constitucionales, Madrid, en prensa.

${ }^{33}$ Ver, sobre todo, Alchourrón, C. y Bulygin, E. «The Expressive Conception of Norms», en Hilpinen, R. New Studies in Deontic Logic, Reidel, Dordretch, 1981, ps. 95-124. 
Alchourrón y Bulygin han presentado a la concepción expresiva en forma no siempre uniforme: en ciertas ocasiones las normas son concebidas como actos y en otras como resultados de actos. Esto se refleja claramente en su exposición: «para la concepción expresiva, las normas son el resultado del uso prescriptivo del lenguaje»; «una oración (...) puede ser usada en diferentes ocasiones para hacer cosas distintas» (aseverar, interrogar, ordenar, conjeturar) y «el resultado de esas acciones será una aserción, una pregunta, una orden o una conjetura»; "para la concepción expresiva las normas son esencialmente órdenes» ${ }^{34} \mathrm{y}$ «ordenar (en el sentido de dar órdenes) es una actividad esencialmente lingüística, un acto lingüístico», de modo tal que «ordenar puede ser descripto como el acto de promulgar una norma $»^{35}$ (todos los subrayados son míos). Creo que la conocida y peligrosa ambigüedad de proceso-producto se halla oculta dentro de las expresiones «orden» y «prescripción», ya que ellas pueden ser entendidas tanto como el acto de ordenar o prescribir, como su resultado. De este modo, introducida esta distinción, parecería que las concepciones expresiva e hilética tienen posibilidades de convivir en una sola teoría, una teoría en la que las normas sean concebidas como oraciones (con significado) o como significados de expresiones resultantes de la ejecución de actos prescriptivos.

La posición de Nino es un tanto extraña, puesto que, consciente de la ambigüedad, se inclina a concebir a las prescripciones como actos y no como resultados, lo que trae consecuencias serias a su teoría: «Es bueno aclarar-dice Nino- que hay otra noción de norma que está estrechamente relacionada con la que se refiere a prescripciones, pero que no denota el acto de prescribir sino el producto material de ese acto, que puede consistir en grafismos o textos o en sonidos»; y termina señalando: «la característica ambigüedad de proceso-producto que tienen algunas palabras obscurece a veces la distinción entre estas dos nociones relacionadas de norma»» (p. 10). La principal consecuencia de esta asunción es que las prescripciones así concebidas quedan descalificadas como componentes de un razonamiento práctico, puesto que -como dice Nino- «si identificamos a las normas con prescripciones, o sea con actos lingüísticos, ellas resultan objetos demasiado «duros» como para entrar en el razonamiento de alguien que razona en base a normas» (p. 12). Creo que esta consecuencia puede evitarse tomando la decisión opuesta a la de Nino, es decir, concibiendo a las normas como resultados de actos y no como los actos mismos, sin negar la existencia e importancia de estos últimos.

\footnotetext{
${ }^{34}$ Alchourrón, C. y Bulygin, E. «The Expressive Conception of Norms», citado ut supra, p.96-7.

${ }^{35}$ Ibídem, p. 100.
} 
En otros estudios Nino ha distinguido tres conceptos de norma muy diferentes desde el punto de vista ontológico, aunque íntimamente relacionados entre sí. El primero «hace referencia a un juicio o proposición que predica de una acción que debe, no debe o puede hacerse». El segundo «se refiere a una prescripción o sea al acto lingǘstico consistente en formular una norma en el sentido anterior». El tercero «hace referencia a un texto escrito que es el resultado de un acto lingüístico como el referido por el sentido anterior» ${ }^{36}$. Sostuve en otra ocasión que es posible articular estas nociones en una sola concepción, identificando y diferenciando tres aspectos distintos y conexos del fenómeno normativo: el acto normativo, el enunciado normativo y la norma ${ }^{37}$. De acuerdo con este punto de vista, el acto normativo es un acto lingüístico, ejecutado por un sujeto determinado en un lugar y tiempo dados, destinado a promulgar una prescripción y, como tal, orientado a dirigir la conducta de determinados sujetos. Por su parte, el enunciado resultante del acto normativo, el enunciado normativo, es una cadena de expresiones del lenguaje natural, gramaticalmente correcta y completa. Finalmente, la norma es el significado del enunciado formulado con motivo de la ejecución del acto normativo ${ }^{38}$. Este esquema explicativo -creo- permite especificar y diferenciar el status lingüístico que a cada uno de los componentes del fenómeno normativo corresponde: pragmático en el caso del acto, sintáctico en el caso del enunciado y semántico en el de la norma. También creo que supera las barreras teóricas que el esquema de Nino impone, sin clausurar las sendas abiertas por él.

(9) Lógica de los juicios normativos. Nino sostiene que el operador «dominante» es el de deber y que los demás pueden definirse en base a él. En su formulación, (1) «si una conducta es debida, la no realización de esa conducta no puede ser debida; (1') ella está prohibida», (2) «cuando es debido no interferir con una cierta conducta, esa conducta está permitida», (3) «una conducta no puede ser debida y no debida al mismo tiempo», (4) «ni puede ser debida y estar prohibida simultáneamente», (5) «una conducta puede no ser debida ni estar prohibida», y (6) «si una conducta es debida ella está permitida,

36 Nino, C. Un país al margen de la ley, Emecé, Buenos Aires, 1992, ps. 47-8 y Fundamentos de derecho constitucional, Astrea, Buenos Aires, 1992, ps. 39-40.

37 Para un análisis más cuidadoso de esta concepción y sus consecuencias teóricas, ver Mendonca, D. Introducción al análisis normativo, citado ut supra, ps. 65-69.

${ }^{38}$ Es interesante señalar que Kelsen anticipó este punto de vista: «debe observarse -advertía Kelsen- que el acto de voluntad, cuyo sentido es una norma, necesita ser diferenciado del acto de habla en el cual se expresa el sentido del acto de voluntad. De las palabras pronunciadas resulta una frase: un imperativo o un enunciado de deber ser. La norma, que es el sentido de un acto de voluntad, es el significado del enunciado que es el producto de un acto de habla en el cual se expresa el sentido de un acto de voluntad» (el subrayado es mío). Ver Kelsen, H. General Theory of Norms, Clarendon, Oxford, 1991 (original 1973), p. 163. 
(6') no solamente en el sentido de que no está prohibida, sino en el sentido de que es debido no interferir con ella» (p. 16). Veamos estas relaciones con más cuidado. Las presentaré formalizadas para su mejor comprensión.
(1) $\mathrm{Op} \div \sim \mathrm{O} \sim$
(2) $\mathrm{O} \sim \mathrm{Vp} \div \mathrm{Pp}$
(3) $\sim(\mathrm{Op} \& \sim \mathrm{Op})$
(4) $\sim(\mathrm{Op} \& \mathrm{Vp})$
(5) $\sim \mathrm{Op} \& \sim \mathrm{Vp}$
(6) $\mathrm{Op} \div \mathrm{Pp}$

(1') $\mathrm{Op} \div \mathrm{V} \sim \mathrm{P}$

(6') $\mathrm{Pp} \cdot(\sim \mathrm{Vp} \& \mathrm{O} \sim \mathrm{Vp})$

Nino fundamenta estas relaciones en base a las nociones de verdad y de posibilidad. Sin embargo, algunas de ellas pueden ser fundamentadas de una manera diferente, sin necesidad de asignar valor veritativo a los juicios normativos, mediante la noción de posibilidad de ejecución de la conducta prescripta. Este es el criterio propuesto por von Wright en Norma y acción $n^{39}$. Distinguiendo entre conjuntos de normas de obligación, de permisión y mixtos (de obligación y permisión), von Wright explica: (a) un conjunto de normas de obligación es consistente si, y sólo si, «es lógicamente posible, bajo cualquier condición de aplicación dada, obedecer todos los mandatos (colectivamente) que se aplican bajo esa condición» ${ }^{40}$; (b) un conjunto de normas permisivas es invariablemente consistente, dado que «los permisos nunca se contradicen $\rangle^{41} ; \mathrm{y}$ (C) un conjunto mixto de normas de obligación y permisión es consistente si, y sólo si, «es lógicamente posible, bajo cualquier condición de aplicación dada, obedecer todos los mandatos colectivamente y hacer uso, individualmente, de cada uno de los permisos que se aplican bajo esa condición $\rangle^{42}$. La conclusión es, pues, la siguiente: asignar valores de verdad a los juicios normativos abre la posibilidad de una lógica de normas, pero la conversa no es válida, dado que la aceptación de que existen relaciones lógicas entre tales juicios no compromete con la tesis de que ellos poseen valores de verdad ${ }^{43}$.

Una cuestión interesante es la que se presenta en las cláusulas (2) y (6), a saber, la noción de no-interferencia. Nino dice que «cuando es debido no

\footnotetext{
${ }^{39}$ Von Wright, G.H. Norma y acción. Una investigación lógica, Tectos, Madrid, 1979 (original 1963).

${ }^{40}$ Ibídem p. 155.

${ }^{41}$ Ibídem p. 155.

${ }^{42}$ Ibídem p. 156.

${ }^{43}$ En este sentido, ver Alchourrón, C. y Bulygin, E. «The Expressive Conception of Norms», citado ut supra. ps.
} 95-6. 
interferir con una cierta conducta, esa conducta está permitida» y que «si una conducta es debida ella está permitida, no solamente en el sentido de que no está prohibida, sino en el sentido de que es debido no interferir con ella». Parece obvio que la no-interferencia reclamada por Nino no es una no-interferencia fáctica sino normativa. Por consiguiente, la cláusula (2) debe ser entendida como una limitación a la autoridad normativa, en el sentido de que debe abstenerse de prohibir la conducta en cuestión. De ser así, (2) sería un caso típico de las llamadas normas de orden superior, esto es, normas que prescriben (ordenan, prohíben o permiten) la ejecución de actos normativos (actos de promulgación o derogación de normas) ${ }^{44}$. La formalización propuesta en (2), sin embargo, podría ser rechazada por mal formada, pues cabe sostener que las normas no pueden ser contenidos de otras normas. La opción sería representar (2) tal como sigue: (2') $\mathrm{O}-\mathrm{Vp} \div \mathrm{Pp}$, según han sugerido Alchourrón y Bulygin, de modo a dejar en claro que, si es obligatorio abstenerse de prohibir una conducta, ella está permitida ${ }^{45}$. De igual manera, la formalización e interpretación de $\left(6^{\prime}\right)$ podría modificarse en el mismo sentido.

Finalmente, algunas acotaciones puntuales. Primero, que las cláusulas (1) y (1') no son equivalentes en el sistema standard de la lógica normativa, tal como parece postular Nino, y que (1') se expresa en ese sistema mediante un bicondicional, esto es, (1") Op Ø V-p; además, que (1) expresa la conocida regla «obligación implica permisión». Segundo, que las cláusulas (3) y (4) expresan relaciones de inconsistencia, (3) entre la obligación y la no-obligación y (4) entre la obligación y la prohibición. Por último, que la cláusula (5) abre la posibilidad de que una conducta no sea obligatoria ni esté prohibida, pero sin especificar su carácter normativo. La tendencia intuitiva sería la de calificar la conducta en cuestión como facultativa, pero ello exigiría una cláusula adicional de la forma: (7) Op v Vp v Fp, de modo a determinar que los operadores son conjuntamente exhaustivos.

(10) Juicios normativos y constatativos. En la construcción de Nino, al igual que los juicios normativos, los constatativos son verdaderos o falsos, pero a diferencia de aquéllos no lo son respecto de hechos normativos sino de hechos sociales, puramente empíricos. Según expuse, Nino hace depender su verdad o falsedad del acaecimiento efectivo del acto prescriptivo que constata y de sus condiciones de ejecución. Esto me parece básicamente

${ }^{44}$ Sobre el tema, ver especialmente von Wright, G.H. «Normas de orden superior», en Bulygin, E. et al. El lenguaje del derecho. Homenaje a Genaro Carrió, Abeledo-Perrot, Buenos Aires, 1983, ps. 457-470.

${ }^{45}$ Sobre la reiteración de operadores deónticos, ver Alchourrón, C. y Bulygin, E. «Von Wright on Deontic Logic and the Philosophy of Law», en Schilpp, P. y Hahn, L. The Philosophy of Georg Henrik von Wright, La Salle, Illinois, 1989. 
correcto, aunque resta, sin embargo, al menos una cuestión controvertida respecto de este ítem.

Sucede que Nino diluye la distinción descripción/ prescripción no sólo al asignar a los juicios normativos valores de verdad, sino también al atribuir carácter regulativo a los juicios constatativos. Según Nino, «es claro que una norma y en especial una norma jurídica también puede identificarse con actos constatativos de prescripciones» (p. 14). Contra la opinión de Nino, pocas cosas me parecen menos claras que ésta: no se ve cómo y por qué un constatativo pueda ser razonablemente equiparado a una norma. Desafortunadamente, esta cuestión resulta tan obvia para Nino que ninguna pista ofrece al respecto.

Se ha detectado en la teoría de Dworkin un defecto similar respecto de sus conocidas proposiciones de derecho, las cuales presentan, a la vez, rasgos propios de las normas y las proposiciones, aún cuando tales propiedades parezcan incompatibles. El resultado de la evaluación ha sido que, al no considerar Dworkin conjuntamente exhaustivos y mutuamente excluyentes al par de conceptos normas y proposiciones normativas (juicios constatativos en la terminología de Nino), su teoría aparenta ser invulnerable pero resulta, en realidad, indefendible ${ }^{46}$. Me temo que la concepción de Nino en manos de un crítico severo correría el mismo destino que la de Dworkin.

(11) Ciencia del derecho. Nino se ha mostrado partidario de un modelo de ciencia jurídica capaz no sólo de describir y sistematizar sino también de reformular abiertamente el orden jurídico, de modo a proveer un sistema de soluciones axiológicamente satisfactorio, más completo, coherente y preciso que el que ofrece el material jurídico original. Nino ha admitido que esta nueva dimensión de la teoría jurídica no es más que una especialización del discurso moral, pero que, a diferencia suya, el discurso valorativo de la ciencia jurídica se desarrolla en dos niveles: en el primer nivel se pretende justificar las normas de cierto sistema positivo, determinando su grado de aceptabilidad a la luz de principios políticos y morales básicos; en el segundo nivel se presupone cierto marco de normas positivas moralmente justificadas y se trata de encontrar soluciones axiológicamente satisfactorias que resulten compatibles con las normas positivas que se consideran válidas ${ }^{47}$. Aunque este modelo no ha sido explicitado en el ensayo que discuto, ha quedado claramente insinuado en él (p. 21) ${ }^{48}$.

${ }^{46}$ La crítica a la que hago referencia proviene de Bulygin. Ver al respecto, Bulygin, E. «Norms, Normative Proposition and Legal Statements», citado ut supra.

47 Este modelo de ciencia jurídica ha sido defendido por Nino en Introducción al análisis del derecho, ps. 338-347 y en Algunos modelos metodológicos de «ciencia» del derecho, ps. 91-109, ambos citados ut supra.

${ }^{48}$ A la cuestión están específicamente dedicados los parágrafos 3 y 4 del Capítulo 3 de su libro Derecho, moral $y$ política, citado en la nota 2 . 
El programa de Nino parece abiertamente incompatible con el programa positivista, en cualquiera de sus principales modelos alternativos. Para Kelsen la ciencia jurídica -si pretende ser tal- debe hallarse depurada, tanto de elementos extranormativos (sociológicos y económicos) como de factores valorativos o ideológicos (morales y políticos). En este modelo, la ciencia jurídica es una ciencia normativa, no porque formule normas, sino porque describe, mediante proposiciones jurídicas, normas jurídicas válidas en cierto ámbito ${ }^{49}$. El planeta de Ross es diferente del kelseniano, puesto que, en su opinión, las proposiciones de una genuina ciencia jurídica deben ser aserciones acerca del derecho vigente, es decir, acerca del conjunto de directivas que probablemente los tribunales tomarán en cuenta en sus decisiones. De este modo, las proposiciones de la ciencia del derecho constituyen, en definitiva, predicciones acerca de las directivas que serán aplicadas por los juzgadores, razón por la que los juristas pueden valerse de aportes provenientes de otras disciplinas (psicología, sociología, economía), las cuales pueden suministrar información acerca del contexto que rodea a los aplicadores ${ }^{50}$.

El modelo elaborado por Alchourrón y Bulygin es todavía distinto y más sofisticado que los anteriores. Estos autores distinguen dos tareas que la ciencia jurídica debe desarrollar: la tarea empírica de determinar qué normas constituyen la base de un sistema jurídico y la tarea normal de sistematizar el derecho, la cual exige la derivación de las consecuencias lógicas de aquélla base y su reemplazo por otra más económica pero normativamente equivalente ${ }^{51}$. De este modo, más allá de las diferencias entre modelos, existe acuerdo dentro del programa positivista en cuanto a que la ciencia jurídica no puede verse comprometida con valoración alguna del derecho, manteniendo una distinción tajante entre el derecho que es y el derecho que debe ser.

Nino, en cambio, sostiene que «los juristas teóricos no se limitan, como lo indicarían los modelos de ciencia jurídica de autores como Kelsen, Ross o Alchourrón y Bulygin, a describir las prescripciones formuladas sino que tienen como tarea central la de proponer soluciones a los jueces y otros agentes jurídicos» (p. 21). Esto es verdad y no hay inconveniente en conceder que los juristas realizan tareas distintas de la mera descripción del derecho existente, cosa que -por cierto- ninguno de los teóricos mencionados niega o desconoce ${ }^{52}$. La discrepancia radica en las decisiones adoptadas

\footnotetext{
${ }^{49}$ Kelsen, H. Teoría pura del derecho, UNAM, México, 1979 (original 1960), ps. 83 y ss.

${ }^{50}$ Ross, A. Sobre el derecho y la justicia, citado ut supra, ps. 29-72 y 105-151.

${ }^{51}$ Alchourrón, C. y Bulygin, E. Introducción a la metodología de las ciencias jurídicas y sociales, Astrea, Buenos Aires, 1974 (original 1971), ps. 29-49 y 111-144.

${ }^{52}$ Tales modelos no pretenden ofrecer una descripción de la actividad de los juristas sitio fijar las bases teóricas, metodológicas y conceptuales para la construcción de una ciencia jurídica acorde con el programa positivista.
} 
acerca de cómo debería encararse la labor de los juristas: Nino pretende preservar y rescatar lo que los juristas efectivamente hacen y las funciones que satisfacen, proporcionando un modelo que se ajuste a esa actividad; los teóricos positivistas, en cambio, intentan desarrollar una genuina ciencia del derecho -puramente cognoscitiva y axiológicamente neutral- ofreciendo para ello modelos de actividad teórica frente al derecho que satisfagan esas exigencias.

En mi opinión, los positivistas tienen razón al advertir que, si se pretende diseñar una auténtica ciencia jurídica en base a los cánones epistemológicos dominantes, es necesario tomar como objeto de estudio al derecho positivo y mantener, en ese ámbito, una actitud valorativamente aséptica. De otro modo, la ciencia jurídica jamás estará asentada sobre bases sólidas y perpetuará su confusión oscilando entre las disciplinas morales, políticas y sociales. Esta ciencia debe ser capaz de describir en términos igualmente neutros cualquier sistema jurídico, sin que tal descripción suponga adhesión o reprobación a sus respectivos regímenes políticos. Toda actividad dirigida a la valoración, creación o modificación de las normas de derecho corresponde a la política jurídica y queda fuera de la órbita científica. 
DOXA 20 (1997) 